\title{
Analisa Karakteristik Mekanis dan Tekno Ekonomi Pembuatan Komposit Batu Bata Merah dari Limbah Gergaji Kayu Karet
}

\section{Mechanical characterization and Techno-economy analysis of red brick composite from waste of rubberwood sawdust.}

\author{
Rika Taslim ${ }^{1 *}$, Inamul Hasan ${ }^{2}$, Misra Hartati ${ }^{3}$, Muhammad Ihsan Hamdy ${ }^{4}$, Merry Siska ${ }^{5}$ \\ Jurusan Teknik Industri, Fakultas Sains dan Teknologi, UIN Sultan Syarif Kasim Riau \\ JL. HR. Soebrantas No. 155 Simpang Baru, Panam, Pekanbaru, 28293 \\ E-mail:rikataslim@gmail.com, ; hasaninamul03@gmail.com; misrahartati@gmail.com; \\ merry.siska@uin-suska.ac.id; m.ihsanhamdy@uin-suska.ac.id
}

\begin{abstract}
ABSTRAK
Inovasi dalam pembuatan batu bata saat ini memiliki tantangan semakin berkurangnya ketersediaan bahan material dasar tanah lempung sebagai bahan utama pembuatan batubata merah sebagai material utama pembangunan perumahan. Untuk menyiasati hal ini, diperlukan suatu alternatif bahan material komposit untuk mengimbangi laju permintaan batu bata yang berakibat pada laju pemakaian bahan dasar tanah lempung dalam produksi batubata merah. Untuk itu penambahan limbah biomassa berupa serbuk gergaji kayu karet dianggap sebuah solusi untuk memproduksi komposit batubata merah berbasis biomassa. Dalam kajian ini, produk komposit serbuk kayukaret dengan tanah lempung menjadi batu bata merah diteliti nilai karakteristik mekaniknya.Proses pembuatan batu bata merah dengan tambahan limbah kayu karet dilakukan dengan metode desain ekperimen dengan beberapa pengujian seperti :(i) uji kuat tekanan dimana hasil terbaik sebesar 61,98\% dan termasuk standar SNI mutu kualitas III dan (ii) uji serap air, diperoleh nilai daya serap air terendah sebesar 21,75\% dengan tambahan 5\% serbuk kayu karet. Untuk Harga pokok produksi batubata komposit ini diperoleh sebesar Rp. 232/unit lebih rendah dibandingkanharga bata konvensional yaitu sebesar Rp.250/unit. Break Even Point diperoleh sebesar 3981 unit selama 4 bulan dan sangat menguntungkan jika diproduksi.
\end{abstract}

Kata kunci: Batu Bata Merah, BEP, Desai Eksperimern, HPP.

\begin{abstract}
Innovations in brick making currently face the challenge of decreasing availability of clay as the main material for making red brick as the main material for housing construction. To get around this, an alternative composite material is needed to compensate for the rate of demand for bricks which results in the use of clay as a base material in the production of red brick. For this reason, the addition of biomass waste in the form of rubber wood sawdust is considered a solution for producing biomass-based red brick composites. In this study, the composite product of wood vapor powder with clay soil into red brick was examined for its mechanical characteristics. The process of making red bricks with the addition of rubber wood waste is carried out by an experimental design method with several tests such as: (i) a pressure strength test where the best results are 61.98\% and include the SNI quality standard III quality and (ii) water absorption test, obtained the lowest water absorption value was $21.75 \%$ with an additional 5\% rubber wood powder. The cost of production of this composite brick is Rp. 232 / unit is lower than the price of conventional brick which is Rp. 250 / unit. Break Even Point was obtained for 3981 units for 4 months and is very profitable if produced.
\end{abstract}

Keywords: Red Brick, BEP, Experimental Design, HPP.

\section{Pendahuluan}

Perkembangan ekonomi di Indonesia saat ini tengah meningkat dengan pesat, hal tersebut ditandai dengan bertambahnya pembangunan infrastruktur. Salah satunya diprovinsi Riau yang saat ini sedang melakukan pengembangan, yang terlihat saat ini dengan banyaknya pembangunan yang berada dimana-mana, seperti gedung- gedung perusahaan, kantor pemerintahan, sekolah, rumah sakit, tempat-tempat usaha dan juga proyek pembangunan perumahan. Sedangkan untuk sektor perumahan dapat di lihat dari peningkatan jumlah KPR dari bank BTN di provinsi Riau tahun. Pada gambar 1 ditampilkan data perkembangan permintaan KPR pada tahun 2016 di provinsi Riau. 
Dari data diatas terlihat perkembangan pembangunan rumah KPR bank BTN perbulannya, Peningkatan permintaan KPR ini tentu berkaitan langsung dengan peningkatan kebutuhan bahan-bahan bangunan salah satu bahan bangunan yang sangat penting adalah batu bata merah. Batu bata merah ini dikenal secara luas karena merupakan salah satu bahan bangunan dasar yang praktis pemakaiannya dan bersifat kuat. Sementara bahan bakunya hanya terdiri dari tanah liat dan air (Handayani, 2010).

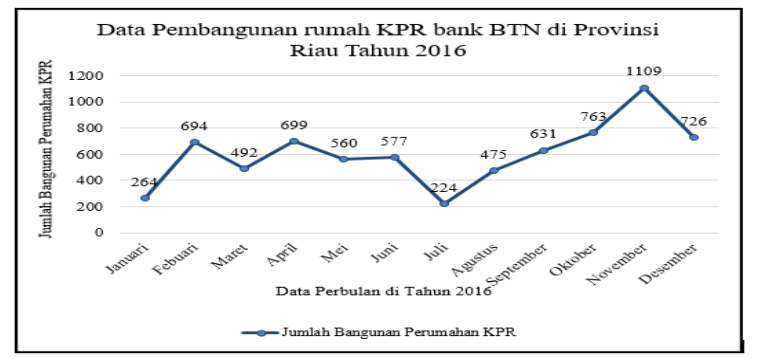

Gambar1. Grafik Perkembangan Pembangunan Rumah KPR

Batu bata merah memiliki berbagai ukuran diantaranya batu bata merah besar dan batu bata merah kecil. Batu bata merah besar dengan ukuran panjang 21 $\mathrm{cm}$; lebar $11,5 \mathrm{~cm}$; dan tinggi $5 \mathrm{~cm}$. Sedangkan batu merah kecil dengan ukuran panjang $15 \mathrm{~cm}$; lebar $10 \mathrm{~cm}$; dan tinggi 3,5 cm. Batu bata ini bertekstur keras, tetapi agak rapuh (Handayani, 2010). Batu bata merah yang bertekstur keras memiliki beberapa kategori standar nasional Indonesia diantaranya terdapat pada tabel 1 (SNI 15-20942000, Badan Standardisasi Nasional, 2000).

Tabel 1. Klasifikasi Kekuatan Batu Bata Merah Menurut Standar SNI

\begin{tabular}{ccc}
\hline Batu Bata & \multicolumn{2}{c}{ Kuat Tekan Rata-Rata } \\
\cline { 2 - 3 } Merah & $\mathrm{Kg} / \mathrm{cm}^{2}$ & $\mathrm{~N} / \mathrm{mm}^{2}$ \\
\hline Tingkat I & Lebih besar dari 100 & $>10$ \\
\hline Tingkat II & $100-80$ & $10-8$ \\
\hline Tingkat III & $80-60$ & $8-6$ \\
\hline
\end{tabular}

Sumber: Badan Standardisasi Nasional, 2000

Dari data klasifikasi kekuatan batu bata merah menurut standar SNI kualitas batu bata merah yang tersedia kebanyakan di pasaran saat ini tidak sampai di Tingkat 1 tetapi hanya bisa sampai di tingkat 3 yaitu dengan kuat tekanan $80-60 \mathrm{Kg} / \mathrm{cm}^{2}$, maka dari itu perlu adanya perbaikan untuk meningkatkan kekuatan batu bata merah yang dihasilkan. Maka dari itu didalam pembuatan batu bata perlu adanya peningkatan kekuatan batu bata merah yang dihasilkan secara efektif, untuk mengurangi dampak negatif yang terjadi tersebut maka perlunya diberikan suatu solusi. Adapun solusinya dengan mulai banyak melakukan inovasi-inovasi yang membantu memperbaiki mutu dan kualitas batu bata yang dihasilkan (Umar, 2018).
Diantara inovasi yang dibuat adalah dengan membuat batu bata komposit dengan campuran plastik. Inovasi tersebut bertujuan untuk membuat batu bata merah menjadi kuat, Pada penelitian batubata dengan campuran plastik dengan hasil uji kuat tekanan pada campuran 20\%-30\% menghasilkan nilai mencapai $100 \mathrm{~kg} / \mathrm{cm}^{2}$, dan ini termasuk kedalam kelas standar tertinggi yaitu kelas I (satu) yang diharapkan dapat memperkokoh dinding bangunan. Selain untuk memperkokoh banguna, nilai tambah yang di peroleh adalah batu bata yang dihasilkan menjadi ringan karena beban terhadap batu bata dapat berkurang menjadi sebesar $1,12 \mathrm{~kg} / \mathrm{cm}^{2}$, berbanding beban pada batu bata merah konfesional sebesar $1,6 \mathrm{~kg} / \mathrm{cm}^{2}$ disamping produk ini dapat memudahkan pemasangan dari segi teksturnya yang tidak rapuh. (Susatyo dkk, 2014).

Pemanfaatan limbah biomassa yang berlimpah khususnya pada limbah kayu karet yang tidak produktif merupakan hal yang harus dipikirkan oleh petani karet ketika pohon karet sudah tidak produktif lagi. Pada saat ini kurangnya pengolahan terhadap kayu karet dan banyak dari petani karet hanya memanfaatkan getah karet untuk di perjual belikan tanpa mengetahui manfaat dari kayu karet yang tidak produktif lagi dikemudian hari selain hanya dimanfaatkan sebagai kayu bakar. Untuk itu pemanfaatan kayu karet ini menjadi bahan campuran batubata dinilai memberikan nilai tambah yang diharapkan dari berbagai aspek, diantaranya selain pemanfaatan limbah kayu juga dapat menjadi alternatif sebagai bahan baku tambahan untuk produk batubata merah yang bahan dasarnya yaitu tanah lempung semakin hari persediannnya semakin menipis.

Kayu karet merupakan spesifikasi kayu yang kurang kuat dan retan terhadap berbagai jamur dan menyebabkan kayu karet kurang diminati dalam hal pengelolahannya untuk produk-produk berbasis kayu seperti furnitur. Pada kayu karet terdapat beberapa kandungan diantaranya holoselulosa sebesar $66,46 \%$, selulosa $48,64 \%$, lignin $33,54 \%$, pentosan $16,81 \%$ yang mana merupakan bagian dari karbohidrat pada tumbuhan, kadar air 4,21\%, kadar abu 1,25\%, kadar silika $0,52 \%$ termasuk kedalam kelarutan kimia pada kayu karet dan merupakan kandungan lateks yang salah satu jenis polimer yaitu polimer alami yang mempunyai sifat elastis (kenyal) yang dapat dicampurkan kedalam tanah liat (Ali, 2015). Ada bagian polimer yang memiliki kekuatan mekanik yaitu polimer yang berikatan menyilang dan memiliki cabang yang menghubungkan antar rantai polimer. Material polimer yang berikatan 
Vol. 6, No. 2, 2020

Jurnal Hasil Penelitian dan Karya Ilmiah dalam Bidang Teknik Industri

menyilang itulah yang membuat polimer lebih elastis (Sunarya, 2013).

Untuk pelaksanaan ide penelitian komposit batubata ini dilakukan di Jl. Kulim, Simpang Jengkol, Pekanbaru di UKM Riko. UKM ini berdiri dari tahun 2006, dengan bisnis utama adalah pembuatan bata merah dengan proses pebuatan yang masih menggunakan cara manual. Penelitian dilakukan dengan metode desain eksperimen terhadap pembuatan batu bata menggunakan tanah liat yang bagi sebagian besar pengusaha batu bata sebagai bahan utama, dan dimana limbah kayu karet digunakan sebagai campuran, tambahan analisa tekno ekonomi juga digunakan untuk meninjau prospek ekonomi sehingga campuran serbuk kayu karet dapat dijadikan pilihan alternatif oleh masyarakat. Selanjutnya dalam penelitian ini diarahkan dalam mengetahui potensi mutu batubata komposit dengan limbah biomassa dalam hal ini adalah limbah gergaji kayu karet dengan melihat nilai uji kekuatan batu bata dan nilai uji serap air serta menghitung analisis tekno ekonomi pengembangan produk tersebut dengan menghitung Harga Pokok Produksi (HPP) dan Break Even Point (BEP).

\section{Metode Penelitian}

Metodologi penelitian yang dilakukan dalam penelitian ini adalah dengan metoda eksperimen dan dilanjutkan dengan analisa tekno ekonomi pada produk. Secara umum langkah-langkah yang dilakukan dapat dilihat dari flowchart yang telah disusun pada Gambar 2.

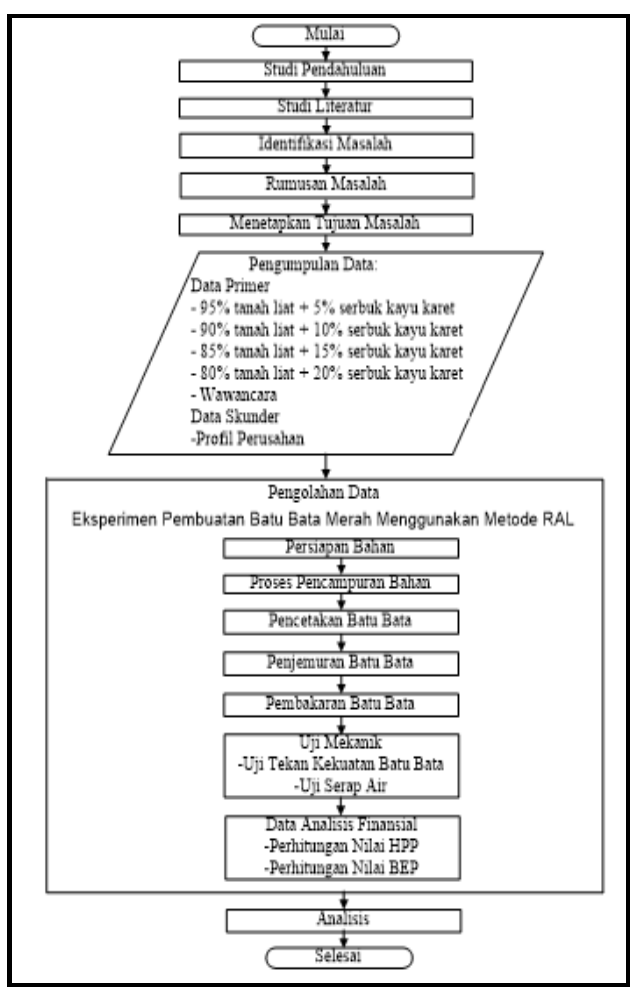

Gambar 2. Flowchart Metodologi Penelitian
Untuk menghasilkan data primer, beberapa langkah eksperimen dilakukan dalam proses pembuatan batu bata dan menjabarkan karakteristik mekanik perhitungan nilai uji kuat tekan dan uji serap air serta selanjutnya menganalisa tekno ekonomi pembuatan batu bata tersebut sebagai berikut:

1. Proses pembuatan batu bata merah

Dalam pembuatan batu bata membutuhkan beberapa proses yaitu:

a. Persiapan bahan

Bahan utama tanah liat dan serbuk kayu karet disiapkan terlebih dahulu. Alat-alat yang digunakan dalam pembuatannya menggunakan wadah atau ember, timbangan dan pencetak batu bata merah. Setelah bahan utama dan alat-alat yang diperlukan terkumpul proses selanjutnya adalah penimbangan dengan menakar antara tanah liat dan serbuk kayu karet dibagi dalam beberapa bagian lalu dilakukan penimbangan masing-masing bahan tersebut secara merata. Takaran yang telah dibagi dibuat kode sampel yaitu BMKT1 yang berarti batu bata merah kayu karet sampel 1 yang mengandung 95\% tanah liat dan 5\% serbuk kayu karet untuk selanjutnya perbandingan sampel dapat dilihat pada tabel 1 berikut.

Tabel 2. Rancangan Penelitian Batu Bata Merah Berbahan Limbah Kayu Karet

\begin{tabular}{lcc}
\hline \multirow{2}{*}{ Takaran } & \multicolumn{2}{c}{ Pembagian } \\
\cline { 2 - 3 } & Tanah Liat & Serbuk Kayu Karet \\
\hline BMKT1 & $1,045 \mathrm{Kg}$ & $0,55 \mathrm{Kg}$ \\
\hline BMKT2 & $0,99 \mathrm{Kg}$ & $0,11 \mathrm{Kg}$ \\
\hline BMKT3 & $0,935 \mathrm{Kg}$ & $0,165 \mathrm{Kg}$ \\
\hline BMKT4 & $0,88 \mathrm{Kg}$ & $0,22 \mathrm{Kg}$ \\
\hline (Sumber: Pengolahan Data, 2019)
\end{tabular}

Keterangan:

BMKT1 : 95\% tanah liat $+5 \%$ serbuk kayu karet

BMKT2 : 90\% tanah liat $+10 \%$ serbuk kayu

karet

BMKT3 : 85\% tanah liat $+15 \%$ serbuk kayu karet

BMKT4 : $80 \%$ tanah liat $+20 \%$ serbuk kayu karet

b. Proses pencampuran bahan

Bahan-bahan yang selesai ditakar menggunakan timbangan selanjutnya dicampur dalam suatu wadah menjadi satu. Wadah yang dipakai dalam pembuatan ini menggunakan ember atau baskom. Setelah bahan baku dimasukan kedalam wadah proses selanjutnya dilakukan pengadukan 
menggunakan tangan karena bahan yang dipakai tidak terlalu banyak dan agar proses pengadukan semangkin cepat dan merata.

c. Pencetakan batu bata merah

Selanjutnya setelah diaduk bahan-bahan tadi dimasukkan kedalam cetakan yang sudah disediakan seperti yang terlihat pada gambar 3, adalah alat pencetak batu bata yang digunakan dalam penelitian ini. Cetakan yang dipakai terbuat dari kayu yang berbentuk balok, Tanah liat yang di masukan kedalam cetakan tersebut di padatkan dan diratakan pinggirannya supaya batu bata tidak hancur atau patah.

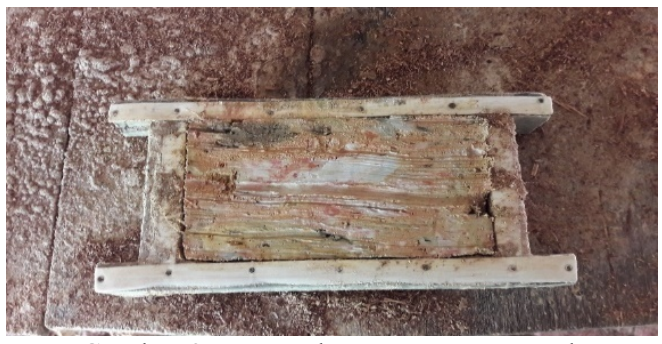

Gambar 3. Pencetakan Batu Bata Merah

d. Pengeringan batu bata merah

Proses selanjutnya adalah proses pengeringan, dimana batu bata yang selesai dicetak dikeringkan, namun tidak terkena matahari langsung hanya memanfaatkan panas yang masuk kedalam ruangan, proses ini dilakukan selama 15 hari didalam suatu ruangan.

e. Proses yang terakhir adalah proses pembakaran. Gambar 4 menunjukan proses pembakaran batu bata yang dilakukan didalam tungku pembakaran yang berlangsung selama 3 sampai 4 hari lamanya pembakaran. Proses ini berfungsi agar tanah liat dan serbuk kayu merekat danbatu bata menjadi keras dan kadar air yang tersisa menjadi hilang.

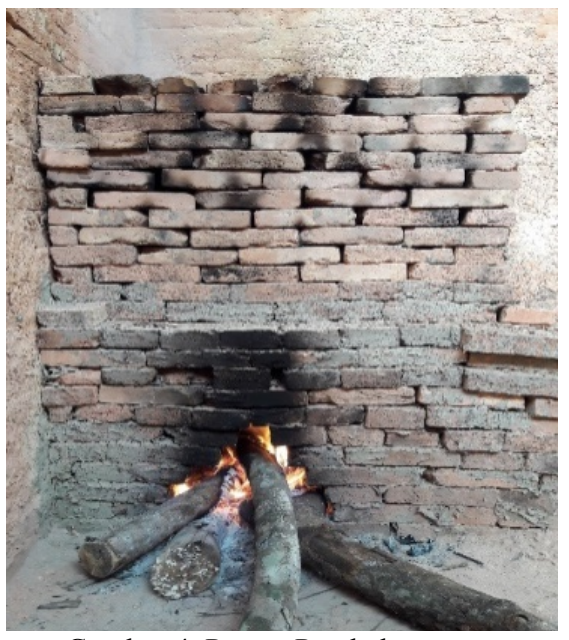

Gambar 4. Proses Pembakaran
Jurnal Hasil Penelitian dan Karya Ilmiah dalam Bidang Teknik Industri

2. Tahap pengujian produk

Pada tahap ini beberapa pengujian dilakukan untuk mengetahui baku mutu batu bata komposit yang dihasilkan dan membandingkan hasilnya dengan batubata konvensional tanpa campuran dari bahan yang lain. Pengujian yang dilakukan adalah diantaranya, Uji Mekanika Batubata, Uji kadar serap air. Selanjutnya juga analisis finansial dilakukan guna mengetahui dan membandingkan nilai mutu batubatakomposit dengan batu bata konvensional.

\section{Hasil dan Pembahasan}

\section{Pengujian Mekanik}

Proses setelah produk batu bata merah berbahan limbah kayu karet selesai dibuat di lakukan beberapa uji mekanik untuk mengetauhi seberapa kuat dan tahannya produk batu bata merah tersebut agar dapat bersaing dengan batu bata dipasaran. Salah satunya uji yang dilakukan sebagai berikut.

1. Uji tekanan kuat batu bata

Uji ini digunakan untuk mengetahui kekuatan atau kemampuan suatu material atau benda untuk menahan tekanan atau beban. Nilai kuat tekan bata diperlukan untuk mengetahui kekuatan maksimum dari suatu benda untuk menahan tekanan atau beban hingga retak dan pecah, serta melihat standar yang sudah di tetapkan. Adapun data yang didapat dari hasil uji batu bata merah konvensional dilihat dari tabel 3, sebagai berikut:

Tabel 3. Data uji yang dihasilkan dari mesin mortar untuk batu bata komposit

Hasil Uji (kN)

\begin{tabular}{lcccc}
\cline { 2 - 5 } Produk & BMKT & BMKT & BMKT & BMKT \\
& 1 & 2 & 3 & 4 \\
\hline Batu Bata 1 & 85 & 13 & 5 & 5 \\
\hline Batu Bata 2 & 83 & 12 & 10 & 6 \\
\hline Batu Bata 3 & 80 & 13 & 6 & 10 \\
\hline
\end{tabular}

Setelah mendapatkan hasil ujinya langkah selanjutnya memasukan nilai hasil uji tersebut kedalam rumus kuat tekanan. Adapun rumusnya sebagai berikut:

$$
\begin{aligned}
\mathrm{P} & =\frac{\mathrm{F}}{\mathrm{A}} \\
& =\frac{85 \mathrm{kN}}{(16 \mathrm{~cm} \times 8,5 \mathrm{~cm})} \\
& =\frac{8667,62 \mathrm{Kg}}{136 \mathrm{~cm}} \\
& =63,732 \mathrm{Kg} / \mathrm{cm}^{2}
\end{aligned}
$$


Keterangan:

P: Kuat tekanan $\left(\mathrm{Kg} / \mathrm{cm}^{2}\right)$

F: Beban yang diterima/tekan $(1 \mathrm{kN}=101,972 \mathrm{Kg})$

A: Luas penampang $\left(\mathrm{cm}^{2}\right)$

Berikut ini adalah data hasil uji kuat tekanan yang diperoleh setelah dihitung dan dapat dilihat pada Tabel 4

Tabel 4. Rekapitulasi Hasil Uji Kuat Tekan Batu Bata Merah

\begin{tabular}{llllll}
\hline \multicolumn{5}{c}{ Hasil Uji Kuat Tekan Batu Bata Merah $\left(\mathrm{Kg} / \mathrm{cm}^{2}\right)$} \\
\hline \multirow{3}{*}{ Produk } & $\begin{array}{l}\text { Batu bata } \\
\text { konvensio- }\end{array}$ & BMKT & \multicolumn{4}{c}{ BMK bata komposit } \\
& nal & 1 & BMKT & BMK \\
& 26,24 & 63,73 & 9,74 & 3,74 & 26,24 \\
\hline Batu Bata 1 & 56,23 & 62,23 & 8,99 & 7,49 & 56,23 \\
\hline Batu Bata 2 & 59,98 & 58,98 & 9,74 & 4,49 & 59,98 \\
\hline Batu Bata 3 & 47,48 & 61,98 & 9,49 & 5,24 & 47,48 \\
\hline Rata-rata & & & &
\end{tabular}

Dari hasil uji kuat tekanan pada tabel 3 dan dirata-ratakan untuk setiap komposisi sampel batu bata yang dihasilkan maka hasil rekapitulasi nilai uji kuat tekan batu bata merah tersebut dapat dilihat pada Tabel 4,dimana hasil pengujian tekanan kuat batu bata merah tertinggi rata-ratanya terdapat pada komposisi campuran 95\%:5\% dengan nilai uji kuat tekannya sebesar $61,982 \mathrm{~kg} / \mathrm{cm}^{2}$, sedangkan pada batu bata konvensional tanpa campuran diperoleh nilainya sebesar rata-rata dengan nilai 47,486 $\mathrm{kg} / \mathrm{cm}^{2}$ dan yang paling rendah pada campuran $80 \%: 20 \%$ dengan nilai rata rata $26,24 \mathrm{~kg} / \mathrm{cm}^{2}$. Berdasarkan data tersebut, batubata komposit dengan campuran 95\%:5\% dengan nilai $61,982 \mathrm{~kg} / \mathrm{cm}^{2}$ sudah termasuk kategori standar mutu kualitas Tingkat III dimana nilai uji tekannya berkisar antara $60-80 \mathrm{~kg} / \mathrm{cm}$ dan yang dinilai bagus dan layak untuk diproduksi dan diperjual-belikan. Pada batu bata konvensional tanpa campuran dengan nilai rata-rata $47,486 \mathrm{~kg} / \mathrm{cm}^{2}$ belum termasuk dalam standar mutu yang yang ditetapkan. Nilai standar mutu batubata konvensional yang rendah dan belum memenuhi standar ini berkemungkinan pihak pengusaha batu-bata konvensional belum pernah melakukan pengujian dan mengevaluasi produk batubata tersebut sebelumnya dan hanya memproduksi batu bata merah dan kemudian menjualnya. Maka dari itu perlu sebuah inovasi dan pengembangan dari batu bata tersebut supaya bisa bersaing dipasaran sehingga dapat menaikan nilai dan mengevaluasi mutu dari produk batu bata itu sendiri.

2. Uji serap air batu bata

Uji ini digunakan untuk menentukan kualitas batu bata yang bagus dengan melihat daya serap airnya. Kualitas batu bata ditandai dengan rendahnya daya serap air terhadap produk. Menurut Susatyo (2014), umumnya bata dianggap baik bila memiliki daya serap air kurang dari 20\% (Susatyo dkk, 2014). Hal ini diketahui dengan mengetahui selisih berat batu bata ketika kering dan ketika basah dan menghitung persentase serap airnya yang kemudian dihitung seperti dijelaskan pada
Jurnal Hasil Penelitian dan Karya Ilmiah dalam Bidang Teknik Industri

persamaan (2) Ada pun data berat batu bata merah pada saat kering (Wk) yang didapat dilihat dari tabel 5:

Tabel 5. Data hasil berat batu bata saat kering (Wk)

\begin{tabular}{llllll}
\hline \multicolumn{5}{c}{ Hasil Berat Batu Bata kering (Wk) (Gram) } \\
\cline { 3 - 6 } Produk & $\begin{array}{l}\text { Batu } \\
\text { bata } \\
\text { konven } \\
\text { sional }\end{array}$ & $\begin{array}{l}\text { BMKT } \\
1\end{array}$ & $\begin{array}{l}\text { BMKT } \\
2\end{array}$ & $\begin{array}{l}\text { BMKT } \\
3\end{array}$ & $\begin{array}{l}\text { BMK } \\
\text { T4 }\end{array}$ \\
\hline $\begin{array}{l}\text { Batu } \\
\text { Bata 1 }\end{array}$ & 759 & 582 & 461 & 430 & 373 \\
\hline $\begin{array}{l}\text { Batu } \\
\text { Bata 2 }\end{array}$ & 720 & 572 & 469 & 428 & 374 \\
\hline $\begin{array}{l}\text { Batu } \\
\text { Bata 3 }\end{array}$ & 747 & 584 & 463 & 432 & 388 \\
\hline Rata-rata & 742 & 579,33 & 464,33 & 430 & 378 \\
\hline
\end{tabular}

Batu bata setelah perendaman dan ditimbang kembali untuk mengetahui seberapa besar penyerapan batu bata terhadap air. Adapun data penyerapannya terlihat pada tabel 6 .

Tabel 6. Data hasil berat batu bata saat basah (Wb)

\begin{tabular}{lccccc}
\hline \multicolumn{5}{c}{ Hasil Berat Batu Bata Basah (Wb) (Gram) } \\
\cline { 3 - 6 } Produk & $\begin{array}{l}\text { Batu bata } \\
\text { merah } \\
\text { konvensional }\end{array}$ & $\begin{array}{l}\text { BMK } \\
\text { T1 }\end{array}$ & $\begin{array}{l}\text { BM } \\
\text { KT2 }\end{array}$ & $\begin{array}{l}\text { BM } \\
\text { KT3 }\end{array}$ & $\begin{array}{l}\text { BM } \\
\text { KT4 }\end{array}$ \\
\hline $\begin{array}{l}\text { Batu } \\
\text { Bata 1 }\end{array}$ & 928 & 745 & 729 & 652 & 631 \\
\hline $\begin{array}{l}\text { Batu } \\
\text { Bata 2 }\end{array}$ & 935 & 734 & 745 & 646 & 612 \\
\hline $\begin{array}{l}\text { Batu } \\
\text { Bata 3 }\end{array}$ & 900 & 772 & 726 & 658 & 609 \\
\hline $\begin{array}{l}\text { Rata- } \\
\text { rata }\end{array}$ & 921 & 750,3 & $\begin{array}{c}733, \\
3\end{array}$ & 652 & $\begin{array}{c}617 \\
3\end{array}$ \\
\hline
\end{tabular}

Setelah didapat berat kering (Wk) dan
berat basah (Wb) langkah selanjutnya
memasukan kedalam rumus serap air (P) untuk
mengetahui berapa persen penyerapan air dari
masing-masing campuran. Adapun caranya
sebagai berikut:

$$
\begin{aligned}
\mathrm{C} & =\frac{\mathrm{Wb}-\mathrm{Wk}}{\mathrm{Wk}} \times 100 \% \\
& =\frac{928 \mathrm{gr}-747 \mathrm{gr}}{747 \mathrm{gr}} \times 100 \% \\
& =\frac{181 \mathrm{gr}}{747 \mathrm{gr}} \times 100 \% \\
& =23,85 \%
\end{aligned}
$$

Keterangan:

$\mathrm{P}$ : Persentase air yang terserap bata (\%)

Wk : Berat bata kering mutlak sebelum direndam air (gr) 
$\mathrm{Wb}$ : Berat bata setelah direndam dalam air (gr) Adapun rekap hasil uji serap air pada batu bata merah dapat dilihat pada tabel 7

Tabel 7. Rekap Hasil Uji Serap Air

\begin{tabular}{llllll}
\hline \multirow{2}{*}{ Produk } & \multicolumn{5}{c}{ Hasil Uji Serap Air Batu Bata Merah (\%) } \\
\cline { 2 - 6 } & $\begin{array}{l}\text { Batu bata } \\
\text { merah } \\
\text { konvension } \\
\text { al }\end{array}$ & Kayu Karet Tidak Produktif & \\
\cline { 2 - 6 } & Asli & BMKT1 & BMKT2 & BMKT3 & BMKT4 \\
\hline $\begin{array}{l}\text { Batu } \\
\text { Bata 1 }\end{array}$ & $23,85 \%$ & $21,48 \%$ & $35,31 \%$ & $29,25 \%$ & $33,99 \%$ \\
\hline $\begin{array}{l}\text { Batu } \\
\text { Bata 2 }\end{array}$ & $24,44 \%$ & $18,61 \%$ & $38,33 \%$ & $30,28 \%$ & $33,06 \%$ \\
\hline $\begin{array}{l}\text { Batu } \\
\text { Bata 3 }\end{array}$ & $24,10 \%$ & $25,17 \%$ & $35,21 \%$ & $30,25 \%$ & $29,59 \%$ \\
\hline Rata-rata & $24,13 \%$ & $21,75 \%$ & $36,28 \%$ & $29,93 \%$ & $32,21 \%$ \\
\hline
\end{tabular}

Dari rekap tabel 7 didapat nilai daya serap paling sedikit terdapat pada takaran 5\% pada campuran batu bata merah berbahan limbah kayu karet yang tidak produktif dengan nilai rata rata $21,75 \%$. Sedangkan pada batu bata konvensional bernilai daya serap sebesar 24,13\%. Dari kedua data tersebut didapat daya serap air paling sedikit yaitu pada campuran batu bata merah berbahan limbah kayu karet tidak produktif dengan takaran 5\%. Namun pada standar SNI daya serap batu bata yang bagus yaitu daya serap kurang $20 \%$, faktor ini disebabkan oleh karena campuran atau pun material yang dipakai yaitu serbuk kayu karet yang memiliki sifat higroskopis yaitu dapat menyerap air dari lingkungannya.

3. Analisis Finansial

a. Perhitungan harga pokok produksi pembuatan batu bata merah berbahan limbah kayu karet menggunakan metode variable costing karena metode ini sesuai digunakan untuk penentuan biaya produksi yang membebankan biaya variabel saja pada produk. Harga per unit pembuatan batu bata merah berbahan limbah kayu karet dapat dihitung dengan total biaya variabel dan dibagikan dengan jumlah produk yang dihasilkan. Perhitungan ini mewakili 32 sampel batubata komposit serbuk kayu karet. Adapun rekapitulasi rincian biaya terlihat pada tabel 8 sebelum dilakukan perhitungan HPP adalah sebagai berikut:

Tabel 8. Rekapitulasi Biaya

\begin{tabular}{clc}
\hline No & Variable Costing & Harga (Rp) \\
\hline 1 & Biaya Bahan Baku & Rp. 456 \\
\hline 2 & Biaya Tenaga Kerja & Rp.3520 \\
\hline 3 & $\begin{array}{l}\text { Biaya Overhead } \\
\text { Variable }\end{array}$ & $\mathrm{Rp} .2120$ \\
\hline \multicolumn{2}{c}{ Total } & Rp.6.096 \\
\hline
\end{tabular}

Jurnal Hasil Penelitian dan Karya Ilmiah dalam Bidang Teknik Industri

Untuk rincian biaya overhead variable dapat dilihat dalam Tabel 9. Berikut ini:

Tabel 9. Biaya overhead variable

\begin{tabular}{clcc}
\hline No & $\begin{array}{c}\text { Biaya Overhead } \\
\text { variable }\end{array}$ & Jumlah & Harga (Rp) \\
\hline $\mathbf{1}$ & Air & 1 liter & Rp.200 \\
$\mathbf{2}$ & Kayu Bakar & 1 lkat & Rp.1.920 \\
\hline \multicolumn{3}{c}{ Total } & RP.2.120 \\
\hline
\end{tabular}

Adapun perhitungan HPP per unit sebagai berikut:

$$
\begin{aligned}
\text { HPP per Unit } & =\frac{\text { Rp. } 6096}{32} \\
& =\text { Rp. } 190,5 / \text { unit }
\end{aligned}
$$

Harga jual yang ditawarkan ke konsumen menggunakan margin sebesar 16\%, dimana batu bata merah kayu karet ini termasuk produk yang baru diproduksi sehingga harga jual yang ditawarkan jauh lebih murah dibandingkan harga yang ada dipasaran. Berikut ini adalah perhitungan harga jual:

Harga Jual

Total Biaya + Laba yan diinginkam

$$
\begin{aligned}
& =\frac{\text { Rp. } 6096+(16 \% \text { x Rp.6096) }}{\text { Total Produksi }} \\
& =\frac{\text { Rp. unit }}{32096+\text { Rp. } 975,36} \\
& =\frac{\text { unit }}{\text { Rp. } 231,51 \approx \text { Rp. } 232 \text { /unit }}
\end{aligned}
$$

Hasil perhitungan harga pokok produksi dengan biaya produksi sebesar Rp 6.096 maka didapatkan harga pokok produksi batu bata merah kayu karet ini sebesar Rp 190,5/unit atau modal awalnya, kemudian ditawarkan ke konsumen dengan keuntungan margin sebesar 16\% dikarenakan haraga batu bata merah kayu karet ini masih baru untuk bersaing dipasaran maka didapatkan harga jual sebesar Rp 232/ unit, sebagai batu bata merah kayu karet alternatif ini jauh lebih murah jika dibandingkan dengan harga batu bata merah kayu karet dipasaran dengan harga berkisar Rp 250/Unit.

b. Perhitungan Break Even Point (BEP)

Break Even Point adalah titik penghasilan dan total biaya yang dikeluarkan dimana suatu keadaan perusahaan tidak menderita kerugian dan belum mencapai keuntungan. Selanjutnya biaya dimasukan ke rekapituasi biaya-biaya yang dikeluarkan pada pembuatan batu bata merah kayu karet dengan menggunakan metode variable costing yang dapat dilihat pada Tabel 10 berikut ini: 


\begin{tabular}{|c|c|c|c|c|}
\hline $\begin{array}{l}\mathrm{N} \\
\mathrm{o}\end{array}$ & \multicolumn{2}{|c|}{ Jenis Biaya } & $\begin{array}{l}\text { Harga } \\
\text { Perhari } \\
(\mathrm{Rp})\end{array}$ & $\begin{array}{c}\text { Harga } \\
\text { Pertahun (RP) }\end{array}$ \\
\hline \multirow{4}{*}{1} & \multirow{4}{*}{$\begin{array}{l}\text { Biaya } \\
\text { Variabel }\end{array}$} & $\begin{array}{l}\text { Biaya } \\
\text { Bahan Baku }\end{array}$ & Rp. 442 & Rp. 132.600 \\
\hline & & $\begin{array}{l}\text { Biaya } \\
\text { Tenaga } \\
\text { Kerja }\end{array}$ & Rp.3520 & Rp.1.056.000 \\
\hline & & $\begin{array}{l}\text { Biaya } \\
\text { Overhead } \\
\text { Variable }\end{array}$ & $\mathrm{Rp} 2.120$ & Rp.636.000 \\
\hline & & Total & Rp.6.096 & Rp.1.828.800 \\
\hline \multirow[t]{2}{*}{2} & $\begin{array}{l}\text { Biaya } \\
\text { Tetap }\end{array}$ & $\begin{array}{l}\text { Biaya } \\
\text { Deprisiasi } \\
\text { Peralatan }\end{array}$ & Rp.553,33 & Rp.166.000 \\
\hline & \multicolumn{2}{|c|}{ Total Keseluruhan } & $\begin{array}{c}\text { Rp.6649,3 } \\
3\end{array}$ & Rp.1.994.800 \\
\hline
\end{tabular}

Adapun perhitungan BEP (unit) dan BEP (Rp) sebagai berikut:

$$
\begin{aligned}
\mathrm{BEP}(\text { unit }) & =\frac{\text { Biaya Tetap }}{\text { Harga jual per unit-variabel per unit }}(5) \\
& =\frac{\text { Rp. } 166.000}{\text { Rp. } 232,2-\text { Rp. } 190,5} \\
& =3980,81 \text { unit } \approx 3981 \text { unit } \\
\operatorname{BEP}(\operatorname{Rp}) & =\frac{\text { Biaya Tetap }}{1-\text { Biaya variabel/penjualan }}(6) \\
& =\frac{\text { Rp. } 166.000}{1-(\text { Rp. } 1.828 .000 / \text { Rp. } 2.227 .200)} \\
& =\frac{\text { Rp } 166.000}{\operatorname{Rp~} 0,179} \\
& =\operatorname{Rp.~} 926.140,28 \approx \text { Rp. } 926.140
\end{aligned}
$$

Berdasarkan hasil perhitungan titik impas dalam produksi 32 unit produk batu bata merah kayu karet perlu setidaknya memproduksi 3981 unit produk batu bata merah kayu karet untuk mengalami kondisi dimana tidak rugi dan tidak untung atau pun balik modal, dengan total pendapatan kotor Rp.926.140. Dari nilai titik impas tersebut maka kembalinya modal akan sangat cepat dengan kurun waktu 124 hari. Hal ini membuktikan bahwa apabila kita memproduksi batu bata merah kayu karet dengan komposisi tersebut maka sudah dikatakan kembalinya modal yang dicapai, sehingga pembuatan batu bata merah kayu karet dari limbah kayu karet yang tidak produktif ini cukup menguntungkan bagi masyarakat dan industri kecil batu bata merah, karena selain mengurangi penumpukan sampah juga dapat menambah pendapatan bagi masyarakat dan bagi industri kecil batu bata merah mendapatkan harga industri kecil batu bata merah yang murah dan terjangkau.

\section{Kesimpulan}

Berdasarkan analisa yang telah dilakukan terhadap pengolahan data yang diperoleh, maka dapat disimpulkan sebagai berikut:

1. Telah dilakukan pembutan batu bata merah berbahan limbah kayu karet dengan 4 takaran yaitu 5\%, 10\%, $15 \%$, dan $20 \%$ serbuk kayu karet serata membandingkan dengan batu bata konvensional. Dari beberapa takaran tersebut didapat hasil uji kuat tekanan tersebut didapat takaran 5\% sebesar 61,982 $\mathrm{kg} / \mathrm{cm} 2$ merupakan nilai yang paling tinggi dan yang paling kuat dan tahan, serata termasuk kedalam standar mutu III dan layak untuk di produksi dan dipasarkan. Uji selanjutnya dilihat dari uji serap air yang dilakukan dengan membandingkan berat kering dan berat ketika basah atau pun dalam keadaan mengandung air adapun hasil uji nilai tersubut ialah batu bata merah takaran 5\% nilai rata ratanya sebesar $21,75 \%$ tersebut merupakan yang paling rendah dalam penyerapan airnya dari itu pada takaran tersebut adalah nilai penyerapan yang rendah dari batu bata konvensional dan beberapa takaran.

2. Harga Pokok Produksi (HPP) pada batu bata merah kayu karet yang didapatkan sebesar Rp 190,5/pcs. Kemudian ditawarkan ke konsumen dengan keuntungan margin sebesar 16\% didapatkan harga jual sebesar Rp 232/pcs, sebagai batu bata merah kayu karet alternatif ini jauh lebih murah jika dibandingkan dengan harga batu bata merah konvensional yang berada dipasaran, seperti batu bata merah konvensional riko berkisar Rp 250/pcs. Pembuatan batu bata merah kayu karet ini yang terbuat dari limbah kayu karet yang tidak produktif ini memiliki nilai positif yaitu tidak merusak lingkungan, memiliki investasi tinggi, komersial yang bagus dan memiliki kos produksi yang rendah dalam pembuatan batu bata merah kayu karet ini, serta mendapatkan nilai tambah dengan memanfatkan limbah tersbut. Break Event Point (BEP) pada batu bata merah kayu karet dalam satuan unit adalah sebesar 3981 unit, dan dalam rupiah sebesar $\mathrm{Rp}$ 926.140. Dari hasil perhitungan Break Event Point pembuatan batu bata merah kayu karet terlihat bahwa total biaya sama dengan total penghasilan, dapat diartikan bahwa batu bata merah kayu karet yang diproduksi harus sebanding dengan pendapatan yang diterima.

\section{Daftar Pustaka}

Ali Farida, Astusi Novi Wulan dan Chairani Nahdia. (2015). Pengaruh Volume Koagulan, Waktu Kontak Dan Temperatur Pada Koagulasi Lateks Dari Kayu Karet Dan Kulit 
Vol. 6, No. 2, 2020

Jurnal Hasil Penelitian dan Karya Ilmiah dalam Bidang Teknik Industri

Kayu Karet. Jurusan Teknik Kimia, Fakultas Teknik Universitas Sriwijaya. Palembang.

Handayani Sri. (2010). Kualitas Batu Bata Merah dengan Penambahan Serbuk Gergaji. Jurusan Teknik Sipil, Fakultas Teknik, Universitas Negeri Semarang. Semarang.

Susatyo, P.A., Watiningsih Tri dan Rustendi Iwan. (2014). Sampah Sebagai Bahan Baku Pembuatan Batu Bata" Prosiding Semnas Entrepreneurship Fakultas Teknik, Universitas Wijayakusuma Purwoketo. Purwoketo

SNI 15-2094-2000. (2000). Bata Merah Pejal Untuk Pasangan Dinding. Jakarta: Badan Standarisasi Nasional.
Suhendra, dkk,. (2015). Karakteristik Fisik Bata Merah dan Kaitannya Dengan Analisa Harga Satuan Pekerjaan. Jurnal Ilmiah Universitas Batanghari Jambi.

Sunarya Yayan. (2011). "Kimia Dasar 2". Bandung: Yrama Widya.

Umar Muhammad. (2018). Uji Kuat Tekanan dan Daya Serap Air Batu Bata Dengan Penambahan Agregat Limbah Cangkang Telur. Repositori Jurusan Fisika, Fakultas Sains dan Teknologi, Universitas Islam Negeri Alauddin Makassar. Makasar, 2018. 